\title{
Study on Thermal Stress of Concrete Beams with Carbon-Fiber- Reinforced Polymers at Low Temperature
}

\author{
Tian Shuai* and Zhang Tong
}

School of Civil Engineering, Liaoning University of Science and Technology, Anshan 114051, China

\begin{abstract}
Concrete beams reinforced with carbon-fiber-reinforced polymers (CFRPs) are subjected to considerable thermal stress at low temperatures. To mitigate this problem, this study conducts a series of tests on three concrete specimens at various temperatures, analyzes the change rule of thermal stress in CFRP-reinforced concrete beams, and discusses the influence of CFRPs on thermal stress in terms of the elastic modulus, thickness, thermal expansion coefficient, beam height, and concrete grade. The results show that when the temperature decreases, CFRP has an obvious restraining effect on the thermal curve of concrete beams. The thermal stress on the interface of CFRP-reinforced concrete beams is sufficiently large and should not be ignored. In particular, in cold areas, thermal stress should be taken into account when reinforcing structures such as concrete bridges. The CFRP sheet's elasticity modulus and thickness are the main factors affecting the thermal stress; in comparison, the expansion coefficient and beam height have lesser effect on the thermal stress; finally, the concrete grade has little effect on the thermal stress. Thermal stress can be prevented feasibly by using prestressed CFRP sheets to reinforce concrete beams. This study can serve as a reference for concrete reinforcement design.
\end{abstract}

Keywords: Carbon-fiber-reinforced polymer (CFRP), concrete beams, low temperature, reinforcement, thermal stress.

\section{INTRODUCTION}

In recent years, carbon-fiber-reinforced polymers (CFRPs) have emerged as a new building material and have been widely used for concrete reinforcement. However, their use in this regard poses some problems. In particular, CFRP's thermal expansion coefficient is negative -(0.6$3) \times 10^{-6}{ }^{\circ} \mathrm{C}^{-1}$ and is much smaller than that of concrete. As a result, when the temperature changes, CFRP and concrete deform differently from and therefore restrain each other. This causes unavoidable thermal stress at the interface of the CFRP sheet and the interior of concrete beams, thus affecting the durability of the concrete reinforcement.

In cold regions, especially, the temperature can change considerably - even by up to $60^{\circ} \mathrm{C}$ - within one year. A large thermal stress will thus be produced in reinforcing concrete beams in structures such as bridges. As an example, Fig. (1) shows a photograph of Tengao Town Bridge, Northeastern China,that was built in 1993 and fully reinforced with CFRPs in 2008. The structure system of this bridge fully consists of a prestressed concrete small box-girder structure. Since this bridge has been opened to traffic, it has often been overloaded, and as a result, many cracks have appeared in its beams. To ensure the bearing capacity of the main beam, after reinforcement, heavy vehicles were strictly restricted from passing over this bridge. In 2010, low-temperature thermal stress damages, as shown in (Fig. 2), began to appear in this bridge; this type of damage is common in cold regions. In this light, it is necessary to study the thermal

\footnotetext{
*Address correspondence to this author at the School of Civil Engineering, Liaoning University of Science and Technology, Anshan 114051, China; Tel: +86-13942206793; Fax: +86-0412-5599006;

E-mail: tian_shuai129@126.com
}

stress induced at low temperatures in CFRP-reinforced concrete beams.

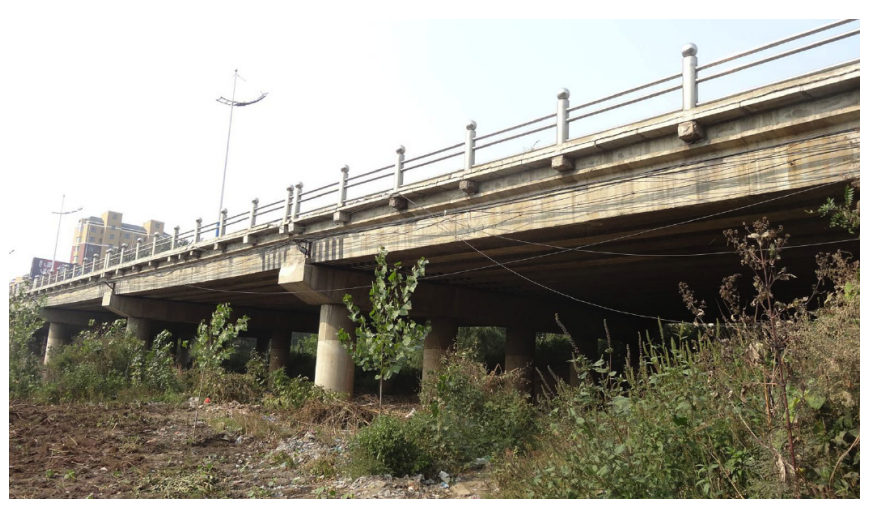

Fig. (1). Full view of reinforced Tengao Town Bridge.

\section{RESEARCH BACKGROUND AND SIGNIFICANCE}

Theoretical and experimental studies have widely focused on the thermophysical properties and behavior of concrete structures reinforced by fiber-reinforced polymer (FRP) materials. Specifically, studies have focused on the fire resistance [1-4], warm temperatures [5], freeze-thaw cycles [6], and other environmental conditions [7-12]. However, few studies have investigated the thermal stress induced in CFRP at low temperatures, which differs from that induced in freeze-thaw cycles.

To bridge this gap, the present study investigates the thermal stress induced in CFRP-reinforced concrete beams at low temperatures through experiments, theoretical derivations, and simulations. A quantitative analysis is used to determine the change rule of thermal stress at low temperature. 


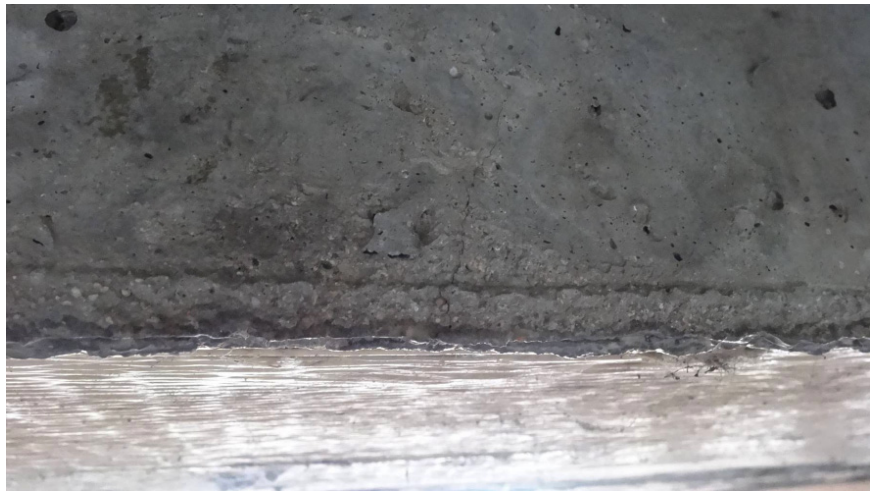

(a)

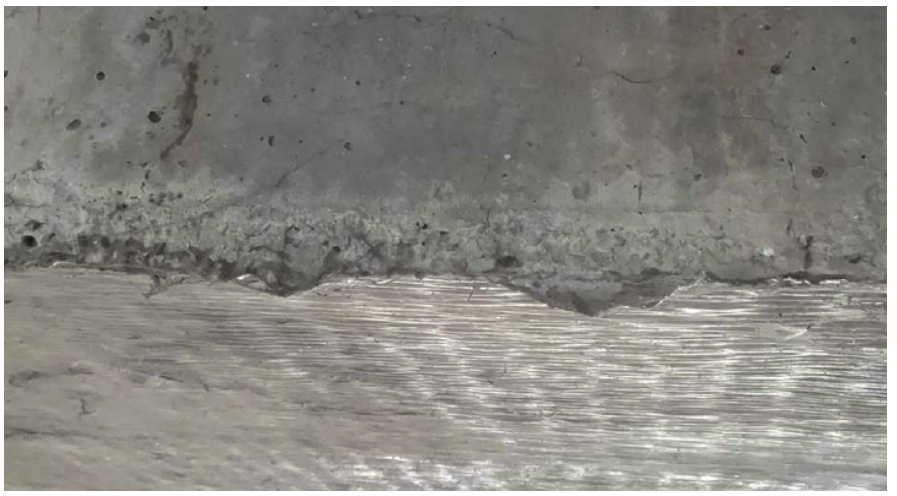

(b)

Fig. (2). Structural cracks caused by thermal stress (a) Cracks (b) Cracks.

The experimental, theoretical, and simulation results show good agreement. From the equations derived, the main factors influencing thermal stress are clarified. Finally, a method to reduce thermal stress is discussed.

\section{EXPERIMENTAL INVESTIGATION}

To experimentally analyze the thermal stress in a CFRPreinforced concrete beam, four specimens - of which nos. 1-3 were test specimens and no. 4 was a compensating specimen-were prepared, as shown in Fig. (3). Fig. (4) shows the size and configuration of the specimens. According to China's concrete code, standard concrete's compressive strength and tensile strength is 20.1 and $2.01 \mathrm{MPa}$, respectively, for specimens consisting of $\mathrm{C} 30$ grade concrete with $\alpha_{c}$ of $1.0 \times 10^{-5}{ }^{\circ} \mathrm{C}^{-1}$ and $E_{c}$ of $3.0 \times 10^{4} \mathrm{MPa}$. After the specimens are aged to 28 days, they are reinforced along their height with CFRPs. An AEC200 CFRP sheet (Taiwan, China) with $0.11-\mathrm{mm}$ thickness was used in this study. According to the CFRP's mechanical performance specifications, $\alpha_{c f}=-1.4 \times 10^{-6}{ }^{\circ} \mathrm{C}^{-1}$ and $E_{c f}=2.35 \times 10^{5} \mathrm{MPa}$. All four specimens were bonded with CFRP sheets. A special CFRP bonding glue (Beijing) was used for this purpose. When reinforcing, bottom glue (AECP), impregnating resin adhesive (AECR), a CFRP sheet, and impregnating resin adhesive (AECR) were applied in order. Both of the glues are twocomponent adhesives and are mixed in the proportion of $4: 1$. A glass sheet is bonded to the beam bottom as a support to ensure that the beam can stretch freely.

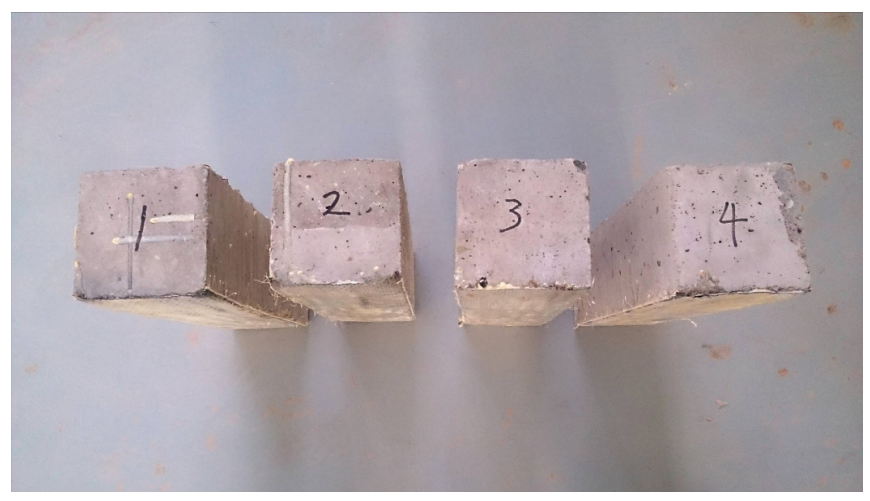

Fig. (3). Thermal stress specimens.
The specimens are placed into a calorstat oven at $20^{\circ} \mathrm{C}$ until their temperature becomes stable. Then, they are preserved in an ice tank, as shown in Fig. (5), where their temperature is successively reduced to $-10^{\circ} \mathrm{C},-20^{\circ} \mathrm{C},-30^{\circ} \mathrm{C}$, and $-40^{\circ} \mathrm{C}$. When the specimens are completely frozen, their thermal stress is measured at different temperatures using an electric resistance strain gauge, shown in Fig. (6). For each test specimen, 15 gauging points are used. At every temperature, the strain is measured at each gauging point once every $30 \mathrm{~min}$, three times in all, and the average of the three measurements is used as the average strain at this point for analysis. Fig. (7) shows the configuration of the strain gauge sheets on specimens; Fig. (8), the testing apparatus; and Fig. (9), a simple graphical flowchart of the testing phases.

At predetermined experimental temperatures, each of the three test specimens had five sectional measuring points, for a total of fifteen sectional measuring points, and their statistical averages were used for analysis. The statistical data showed that the strain of CFRP-reinforced concrete specimens had a linear distribution along the beam height that satisfies the plane section assumption. By the least squares method, linear equations were obtained for every temperature with strain $\varepsilon$ as the dependent variable and $x$ as the position coordinate, as shown in Fig. (10).

In these figures, $\chi$ is the position coordinate (unit: $\mathrm{cm}$ ). At the bottom and top edges of the specimens, $\chi=0$ and $\chi=15$, respectively. $\varepsilon$ denotes the strain (unit: $\mu \varepsilon$ ).

The strain values are calculated at the measured points, interface, and top of the concrete specimen at every experimental temperature according to Fig. (10). Then, the measured values are considered the experimental strain values; the strain of normal concrete and CFRP caused by temperature is considered the free strain; and the difference between the experimental and free strain is considered the restrain strain. The restrain strain is multiplied by the elastic modulus of CFRP and concrete, respectively, to obtain the corresponding thermal stress. The results, shown in Table 1, indicate that when the temperature drops, the CFRP has an obvious restraining action on the thermal curve of concrete specimens. With the difference in temperature, a compressive stress is produced on the CFRP. The bottom of the specimens bears tension. The tensile stress at the concrete interface is the largest. The top of the specimens bears pressure. 


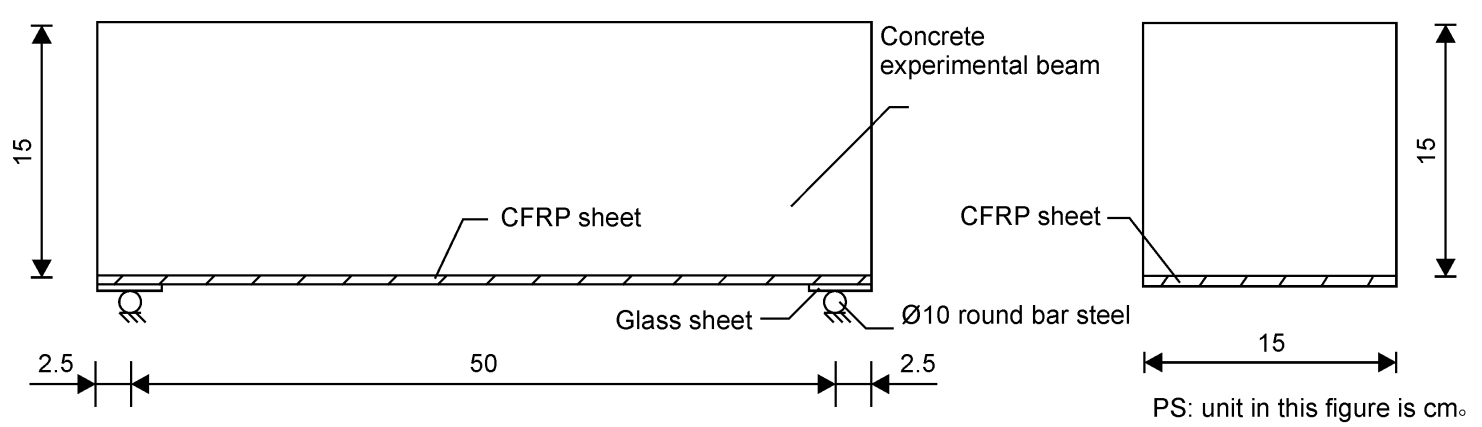

Fig. (4). Size and configuration of specimens.

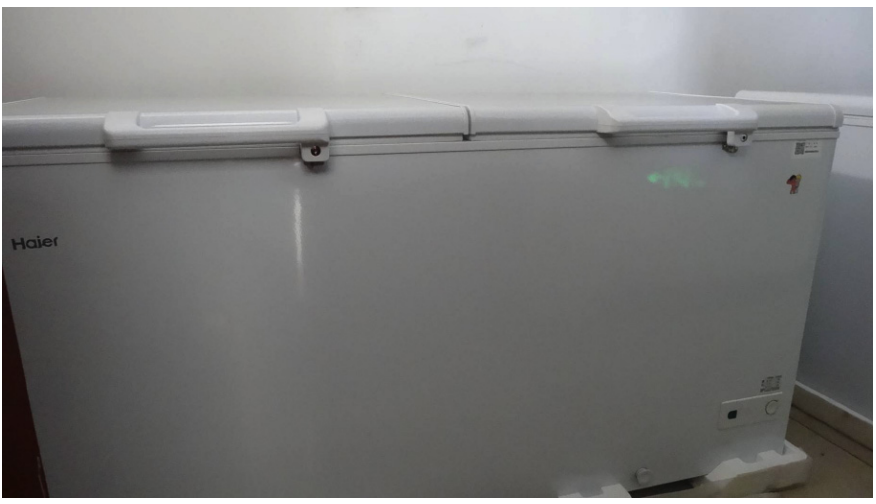

(a)

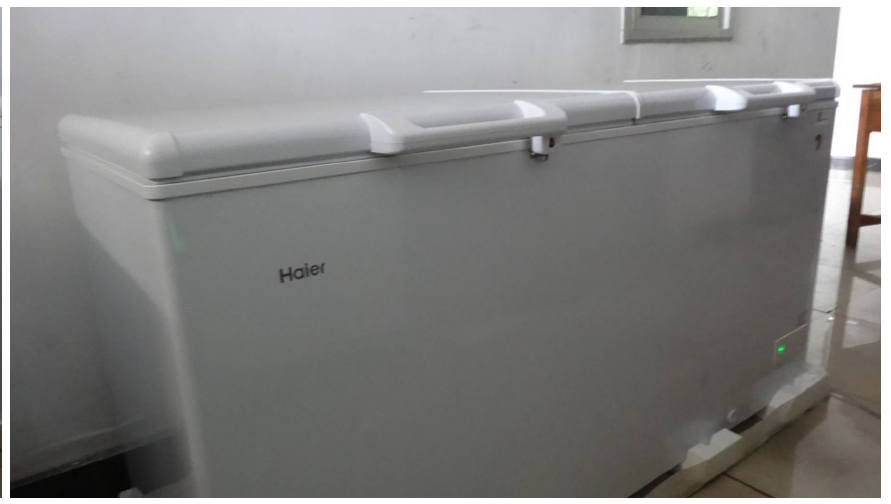

(b)

Fig. (5). Refrigeration equipment (a) calorstat oven (b) ice tank.

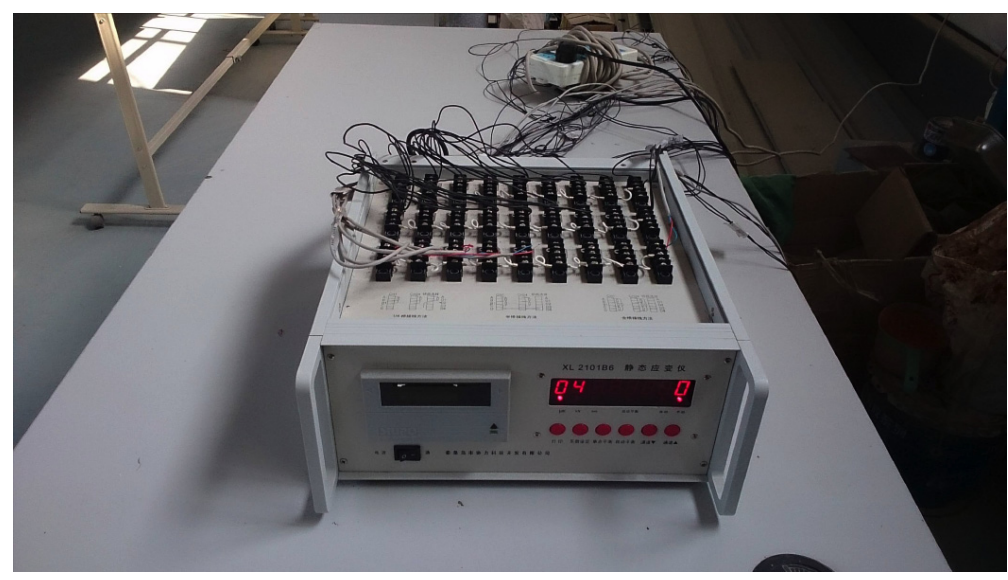

Fig. (6). Electric resistance strain gauge.

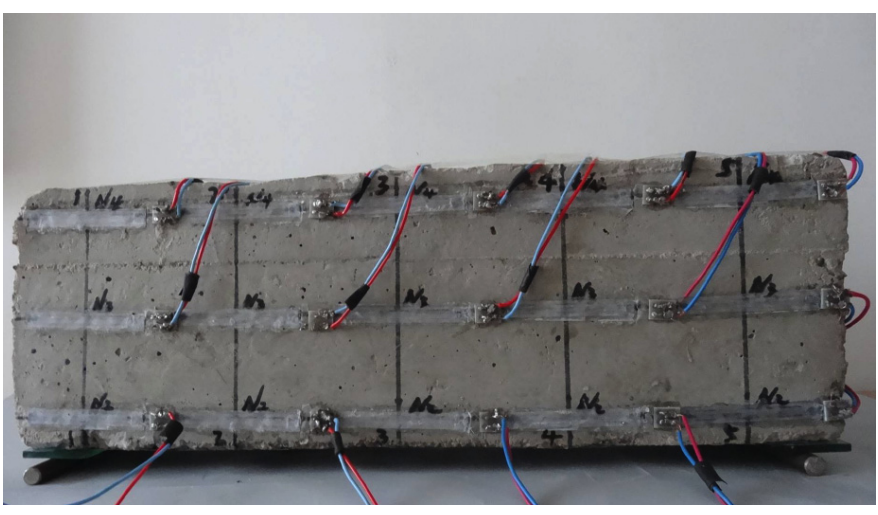

(a)

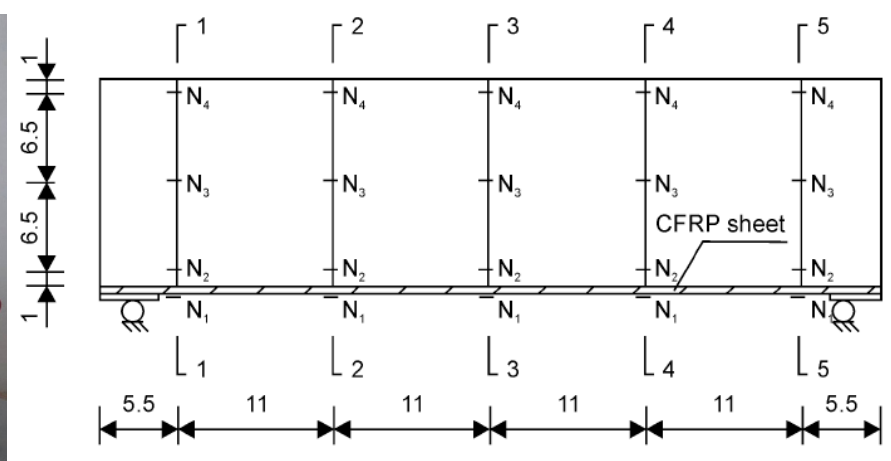

PS: unit in this figure is $\mathrm{cm}$ 。

(b)

Fig. (7). Configuration of strain gauge sheet (a) strain gauge sheet (b) size details. 


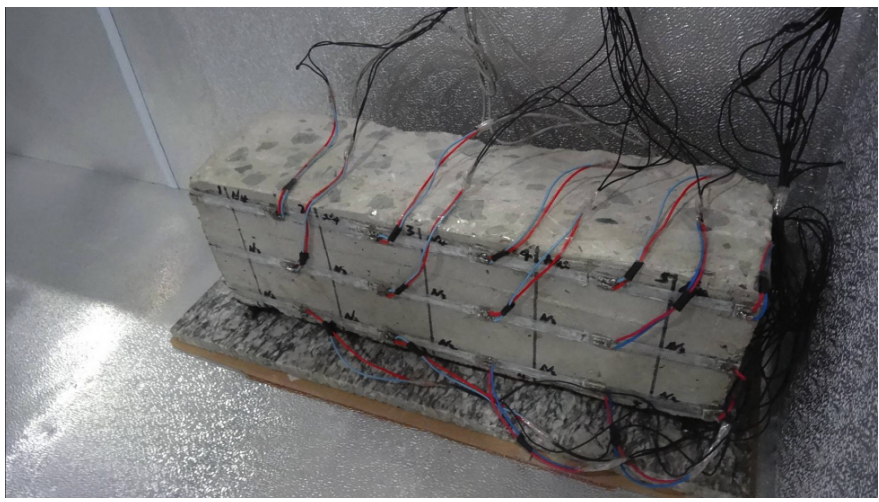

(a)

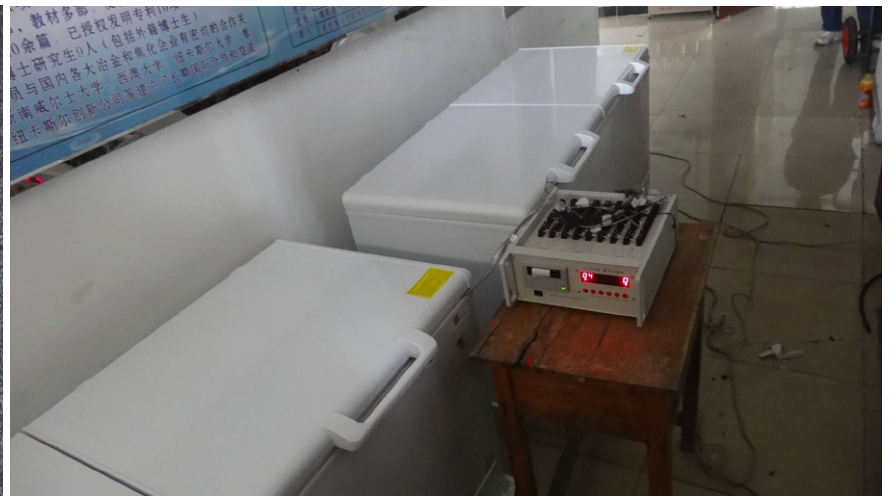

(b)

Fig. (8). Testing apparatus (a) specimen in ice tank (b) testing apparatus.

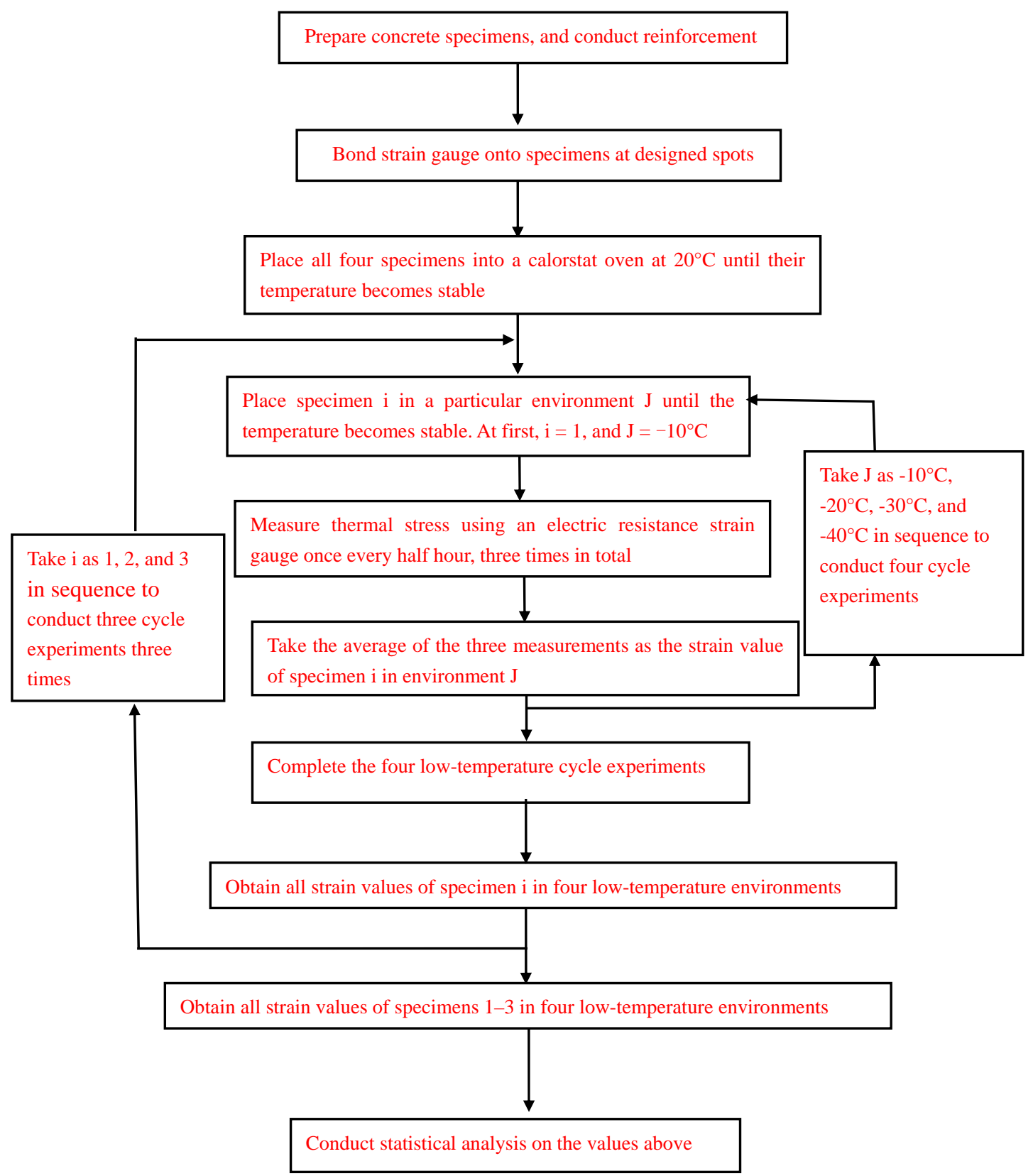

Fig. (9). Flowchart of testing phases. 


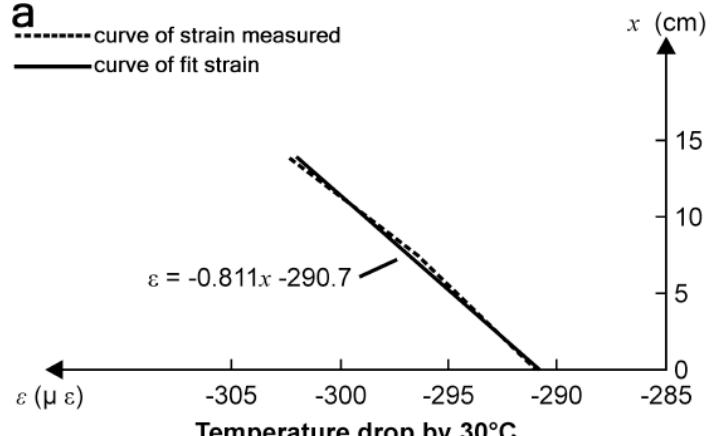

C Temperature drop by $30^{\circ} \mathrm{C}$

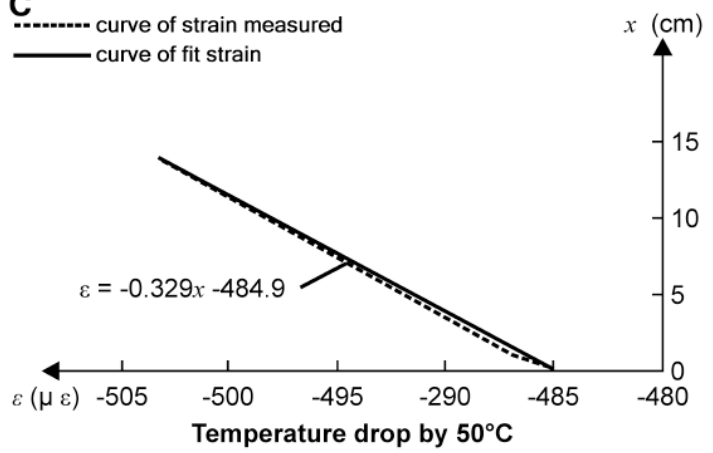

b...... curve of strain measured
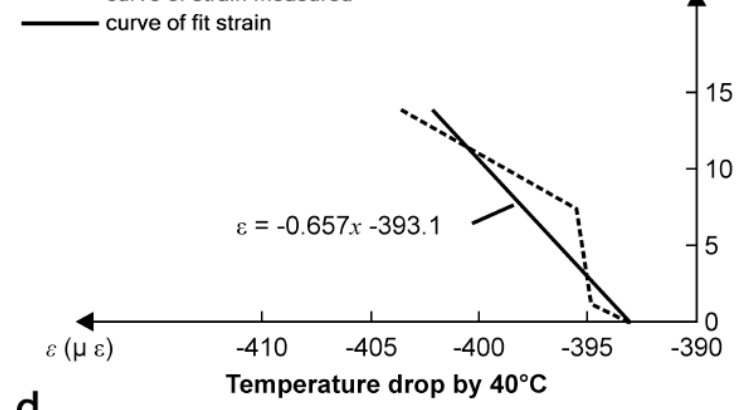

d

-...-.-.- curve of strain measured

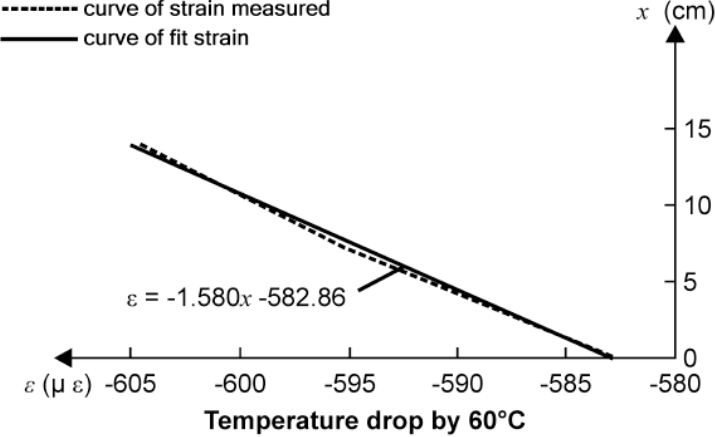

Fig. (10). Function relationship between $\varepsilon$ and $\chi$.

Table 1. Values of restrain strain and thermal stress.

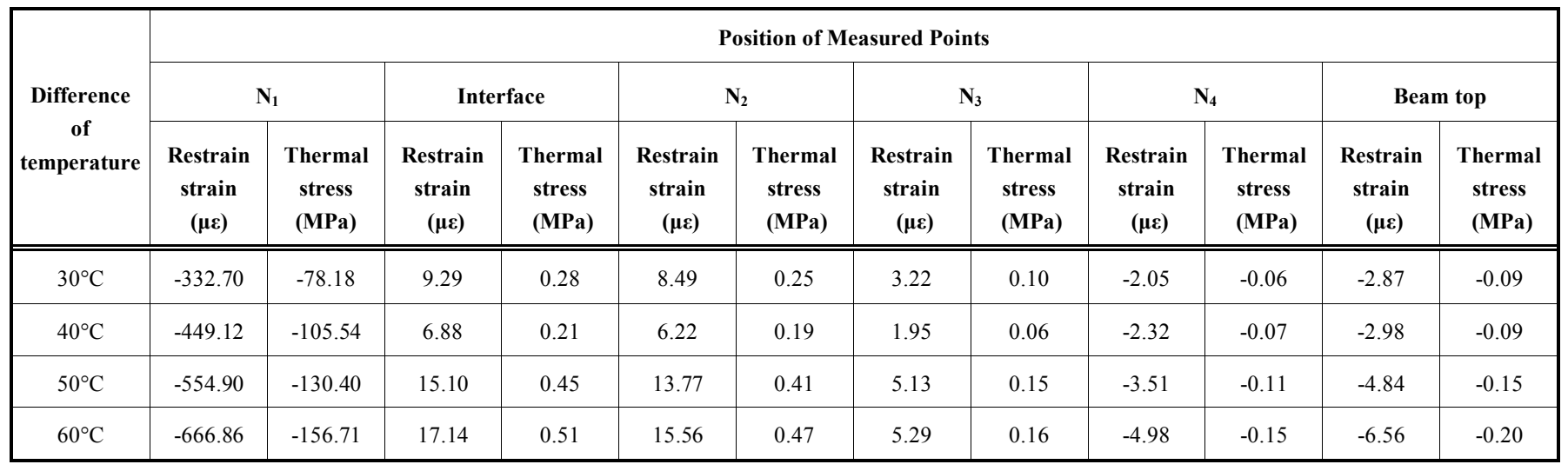

PS: "-" stands for compressive stress; "+" stands for tensile stress

\section{THEORETICAL RESEARCH OF THERMAL STRESS}

\section{Analytical Values of Thermal Stress}

If CFRP sheets are reliably bonded to concrete elements, no slippage would occur. Fig. (11) shows the sectional force analysis of a concrete element unit.

When the temperature drops by $\Delta t$, the interfacial deformation between the CFRP sheet and the concrete element should cohere. In the following equations, $\alpha_{c}$ and $\alpha_{c f}$ are the thermal expansion coefficients of concrete and CFRP, respectively; $d \triangle c$ and $d \triangle c f$ are the elongation of concrete and shortening amount of the CFRP sheet, respectively; $A_{c}$ and $A_{c f}$ are the sectional areas of concrete and the CFRP sheet, respectively; $\gamma_{1}$ and $\gamma_{2}$ are the distances from the centers of concrete and the CFRP sheet, respectively, to the interface; and $\gamma$ is the distance between the center of the concrete element and that of the CFRP sheet. $N_{c}$ and $N_{c f}$ are axial forces acting on the centers of sections of concrete and the CFRP sheet, and $M_{c}$ and $M_{c f}$ are bending moments of sections of concrete and the CFRP sheet.

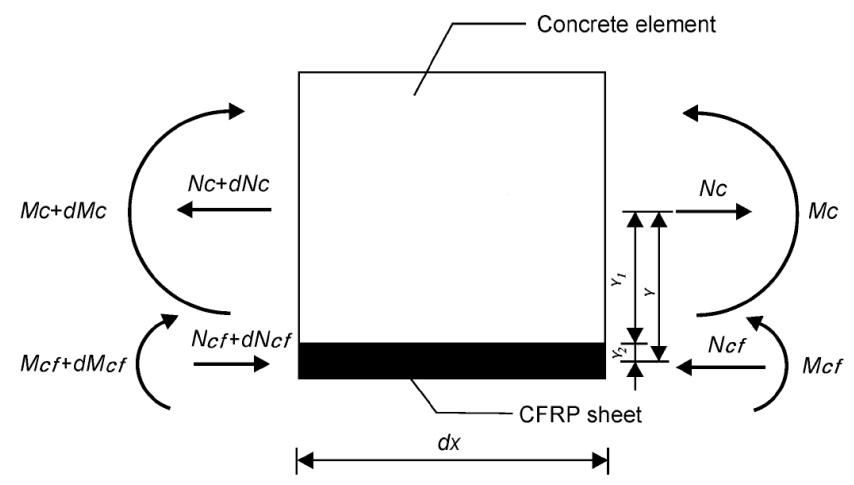

Fig. (11). Force diagram of a concrete element unit. 


$$
\alpha_{c} \Delta t d x-d \Delta c=\alpha_{c f} \Delta t d x+d \Delta c f
$$

No external force acts on the element, and the internal force must maintain the balance, assuming

$$
N_{c}=N_{c f}=N, M_{c}+M_{c f}=N_{c} \gamma
$$

According to the mechanics of materials,

$$
M_{c}=\frac{E_{c} I_{c}}{R_{c}}, M_{c f}=\frac{E_{c f} I_{c f}}{R_{c f}}
$$

The curvature radius of the concrete $R_{c}$ and CFRP sheet $R_{c f}$ at the interface is equal. According to equations (2) and (3),

$$
M_{c}=\frac{E_{c} I_{c} N r}{E_{c} I_{c}+E_{c f} I_{c f}}, M_{c f}=\frac{E_{c f} I_{c f} N r}{E_{c} I_{c}+E_{c f} I_{c f}}
$$

The elongation of concrete $d \Delta c$ and the shortening of the CFRP sheet $d \triangle c f$ at the interface are respectively given by

$$
\begin{aligned}
& d \Delta c=\left[N_{c}+\frac{d N_{c}}{2}\right] \frac{d x}{E_{c} A_{c}}+\left[M_{c}+\frac{d M_{c}}{2}\right] \frac{d x}{E_{c} I_{c}} \gamma_{1} \\
& d \Delta c f=\left[N_{c f}+\frac{d N_{c f}}{2}\right] \frac{d x}{E_{c f} A_{c f}}+\left[M_{c f}+\frac{d M_{c f}}{2}\right] \frac{d x}{E_{c f} I_{c f}} \gamma_{2}
\end{aligned}
$$

Substituting equations (4)-(6) into equation (1) and ignoring high-order micro-quantities gives

$N_{c}=N_{c f}=N=\frac{E_{c} A_{c} E_{c f} A_{c f}\left(E_{c} I_{c}+E_{c f} I_{c f}\right)\left(\alpha_{c}-\alpha_{c f}\right) \Delta t}{\left(E_{c} A_{c}+E_{c f} A_{c f}\right)\left(E_{c} I_{c}+E_{c f} I_{c f}\right)+\gamma^{2} E_{c} A_{c} E_{c f} A_{c f}}$

According to equations (4) and (7), the thermal stress caused by temperature drop $\Delta t$ can be analytically given by able for 3D stable stage and transient state analysis. Unit Solid45, which corresponded to Unit Solid70 used in the thermal analysis, was adopted in the structural analysis. It consisted of eight nodes, and each node had degrees of freedom in three directions for translational motion. It had the properties of plasticity, peristalsis, creepage, and stress stiffening. For CFRP materials, Unit Shell57, a quadrangle with four nodes, was adopted in the thermal analysis. It had only one degree of freedom (temperature), and it is therefore suitable for 3D stable stage and transient state analysis. Unit Shell63, which corresponded to Unit Shell57 used in the thermal analysis, was adopted in the structural analysis. It was a quadrangle with four nodes, and it had six degrees of freedom (three degrees of freedom for translational motion and three degrees of freedom for turning motion). It had the property of membrane bending and was suitable for stress stiffening and large deformation.

By the mapped meshing method, the experimental beam (Fig. 4) was divided into 400 units of concrete and 40 units of CFRP. The entity model figure is shown in Fig. (12) and the finite element figure, in Fig. (13). A horizontal sliding support is used on both ends of the experimental beams, and therefore, the zero point of temperature is at the mid-section of the beam span. For boundary conditions, a displacement constraint was applied to the supporting points vertically, on the nodal points of the beam span mid-section axially, and on the nodal points of the beam axes horizontally. Fig. (13) shows a simulation of the horizontal sliding support and the vertical and horizontal zero point of temperature. When the temperature drops were $30^{\circ} \mathrm{C}, 40^{\circ} \mathrm{C}, 50^{\circ} \mathrm{C}$, and $60^{\circ} \mathrm{C}$, the simulation analysis was conducted on the CFRP-reinforced experimental beam using ANSYS software.

Figs. (14 and 15) respectively show the concrete and the CFRP stress map for a temperature difference of $40^{\circ} \mathrm{C}$. According to these stress maps, the stress was concentrated at the margin of the bonding interface between the concrete

$$
\begin{aligned}
& \begin{array}{l}
\sigma_{\text {superior border of concrete beam }} \\
\sigma_{\text {inferior border of concrete beam }}
\end{array}=\frac{E_{c} A_{c} E_{c f} A_{c f}\left(E_{c} I_{c}+E_{c f} I_{c f}\right)\left(\alpha_{c}-\alpha_{c f}\right) \Delta t}{\left(E_{c} A_{c}+E_{c f} A_{c f}\right)\left(E_{c} I_{c}+E_{c f} I_{c f}\right)+\gamma^{2} E_{c} A_{c} E_{c f} A_{c f}}\left(\frac{1}{\mathrm{~A}_{c}} \mp \frac{E_{c} \gamma \gamma_{1}}{E_{c} I_{c}+E_{c f} I_{c f}}\right) \\
& \sigma_{\text {superior border of CFRP sheet }}=\frac{E_{c} A_{c} E_{c f} A_{c f}\left(E_{c} I_{c}+E_{c f} I_{c f}\right)\left(\alpha_{c}-\alpha_{c f}\right) \Delta t}{\left(E_{c} A_{c}+E_{c f} A_{c f}\right)\left(E_{c} I_{c}+E_{c f} I_{c f}\right)+\gamma^{2} E_{c} A_{c} E_{c f} A_{c f}}\left(-\frac{1}{A_{c f}} \mp \frac{E_{c f} \gamma \gamma_{2}}{E_{c} I_{c}+E_{c f} I_{c f}}\right) \\
& \sigma_{\text {inferior border of CFRP sheet }}
\end{aligned}
$$

\section{Simulation Values of Thermal Stress}

ANSYS is a general-purpose finite element analysis software that is applied to structural, heat, fluid, electromagnetism, and acoustics studies. It is widely used in the field of civil engineering. This study analyzed CFRP-reinforced concrete beams by the indirect method, beginning with thermal analysis of the structure to obtain the node temperature. Upon returning to the preprocessor, thermal units are transformed to corresponding structural units, and the temperature obtained in the thermal analysis is applied to the structural units as body loads. Finally, the structural stress and deformation are obtained by the finite element method.

For concrete materials, Unit Solid70, a hexahedron with eight nodes, was adopted in the thermal analysis. It had only one degree of freedom (temperature), and it is therefore suit- beams and the CFRP sheet, especially at angle points and sidelines. Compressive stress is produced in the CFRP sheet, with the largest stress at its center. The stress decreases at angle points and sidelines, but the amplitude is small. Tensile stress is produced at the concrete interface, and it is smaller at the center and larger at angle points and sidelines. The tensile stress at angle points is 4.2 times that at the center. In both concrete and CFRP, the thermal stress distribution at the center of the interface is uniform, and the distribution area is large. This means that the thermal stress at the center is typical in nature.

\section{ANALYSIS OF THERMAL STRESS}

\section{Analysis on Rule of Thermal Stress}

According to equations (8) and (9) and the model established by ANSYS, the analytical and simulated values of 


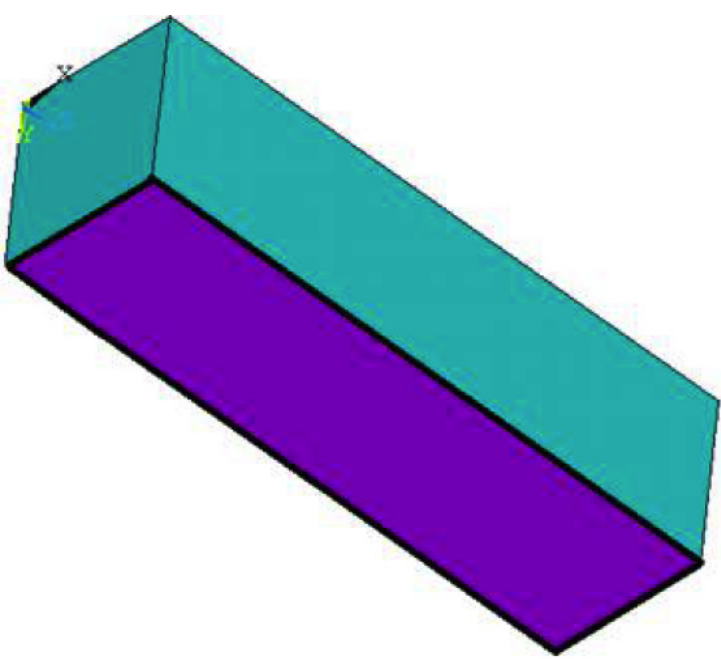

Fig. (12). Entity model figure.

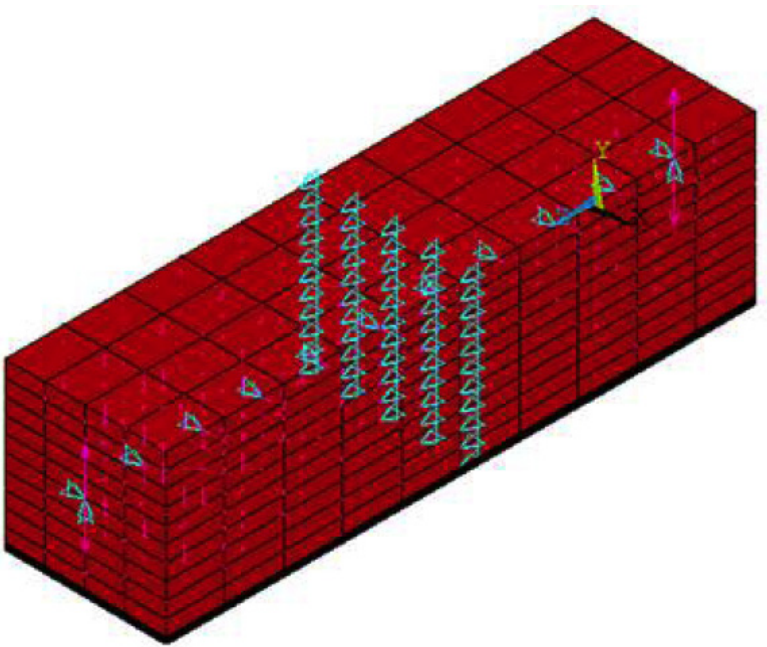

Fig. (13). Finite element figure.

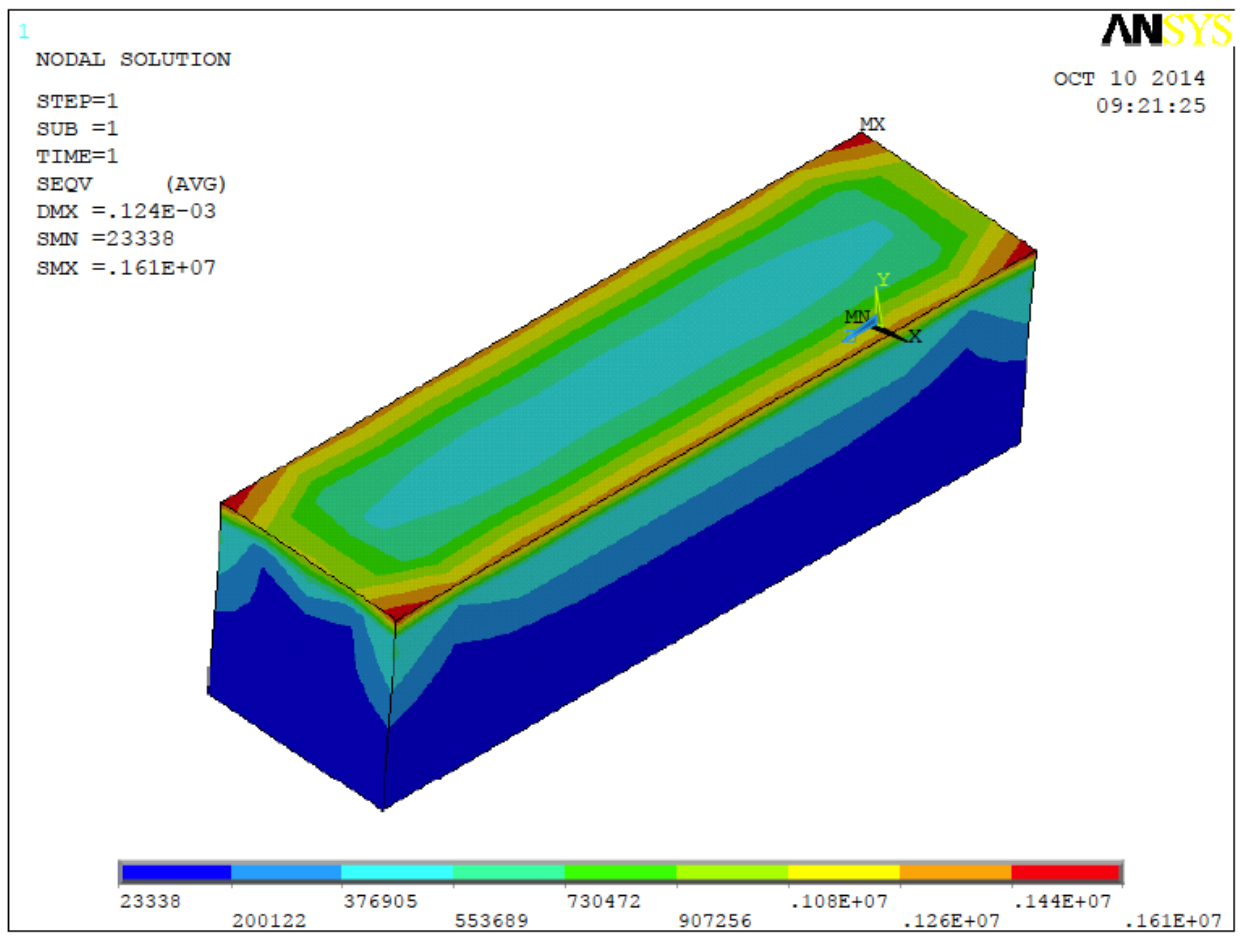

Fig. (14). Concrete stress map for temperature difference of $40^{\circ} \mathrm{C}$ (CFRP on top).

thermal stress for the experimental beams shown in (Fig. 4) were calculated. The analytical and simulated values and measured values (in Table 1) were plotted as distribution curves at every experimental temperature, as shown in Fig. (16).

Fig. (16) shows that the measured, analytical, and simulation values of thermal stress are basically consistent and in agreement with each other, suggesting that the values measured in this study are reliable and that the analytical equations and simulation models are relatively precise. Owing to the temperature difference, tensile stress is produced at the concrete interface. When the temperature drops by $60^{\circ} \mathrm{C}$, the maximum tensile stress is close to $0.5 \mathrm{MPa}$, which is $24.8 \%$ of the standard tensile strength of $\mathrm{C} 30$ concrete $(2.01 \mathrm{MPa})$.
Thermal compressive stress is produced on the CFRP sheet, and the maximum compressive stress reaches $156.71 \mathrm{MPa}$, which is $\sim 3.7 \%$ of the design strength of $4200 \mathrm{MPa}$. Because of the stress redistribution caused by the temperature difference, compressive stress is produced at the superior border of the experimental beam, and the compressive stress reaches $1.1 \%$ of the standard compressive strength of $\mathrm{C} 30$ concrete $(20.1 \mathrm{MPa})$. Although the proportion of stress on the concrete and the CFRP sheet is low, large tensile stress remains on the tensile area of concrete. Tensile stress can cause cracks on concrete beams even when the load is small, which should not be ignored. Therefore, when reinforcing concrete with CFPR sheets in cold areas, the thermal stress should be taken into consideration. As shown in these stress maps, with 


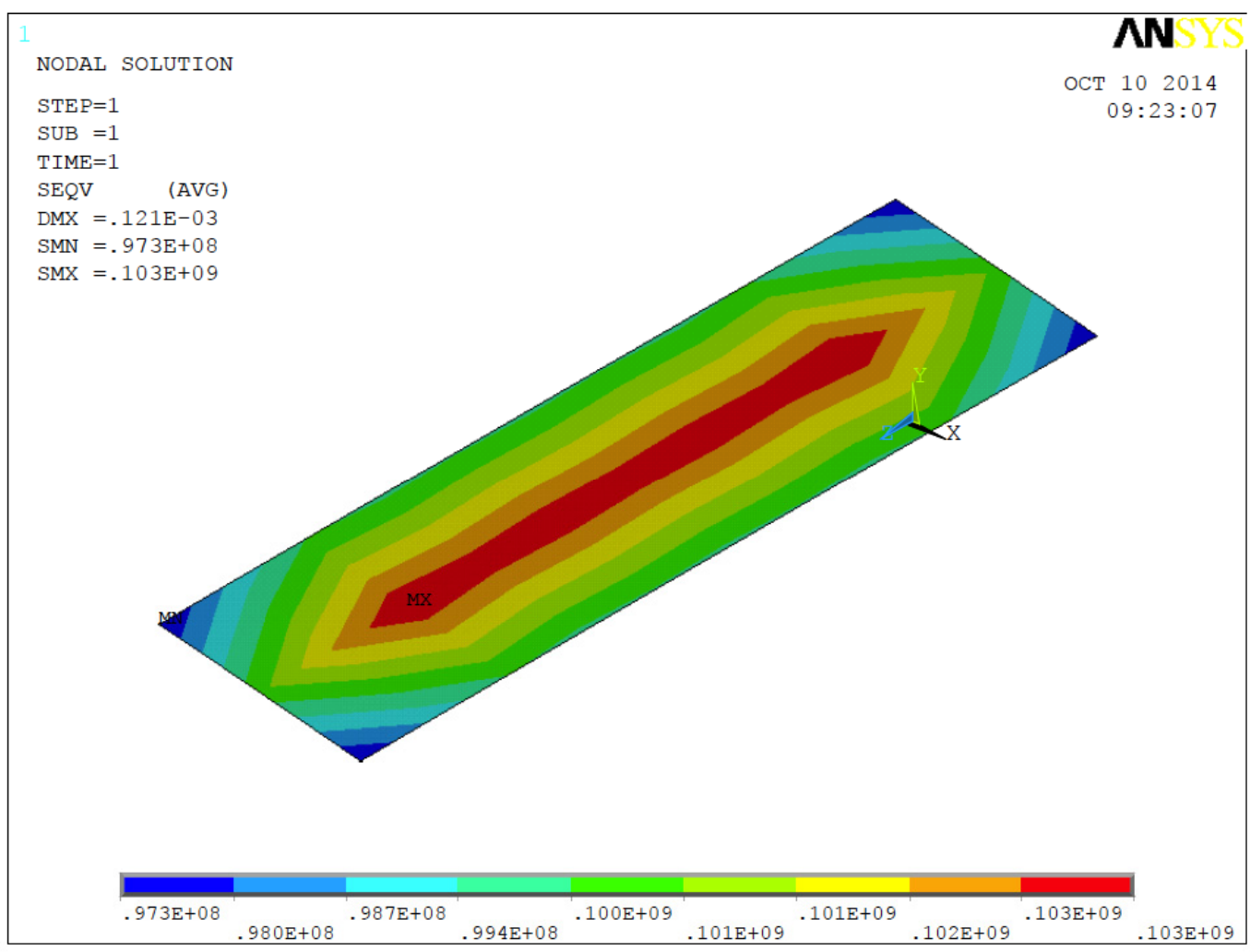

Fig. (15). CFRP stress map for temperature difference of $40^{\circ} \mathrm{C}$.

a

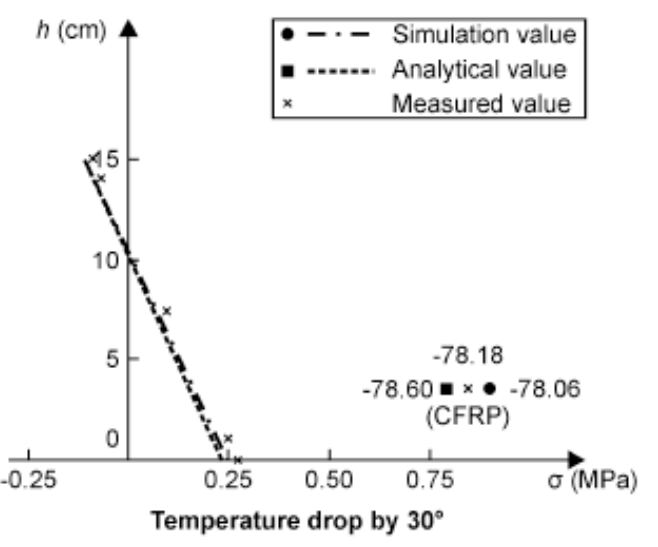

C

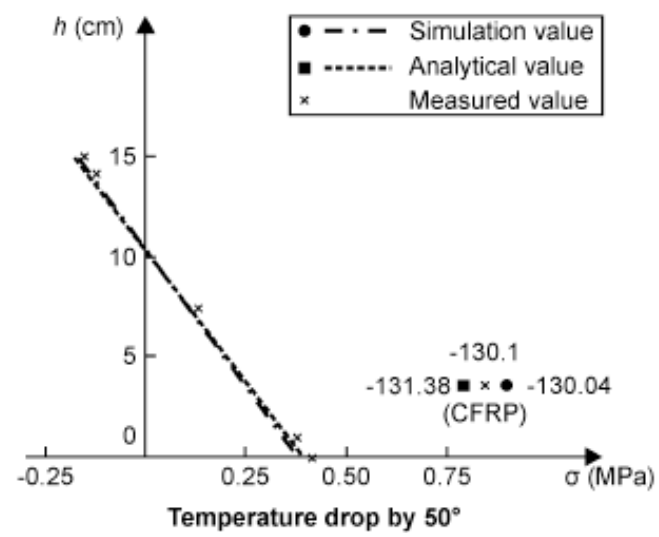

b

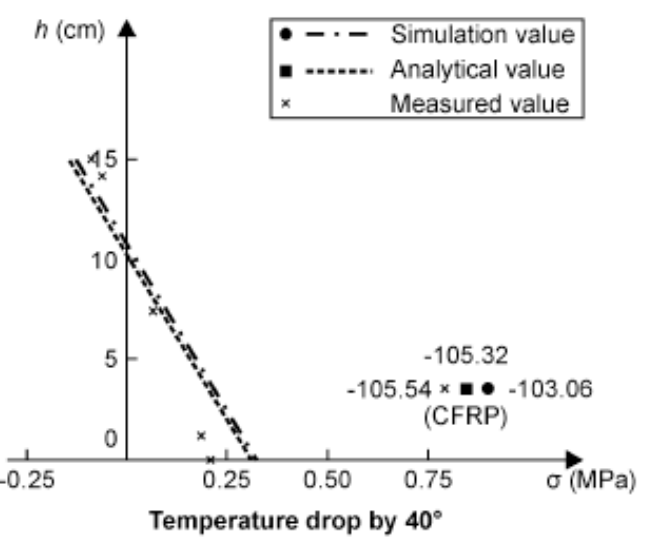

d

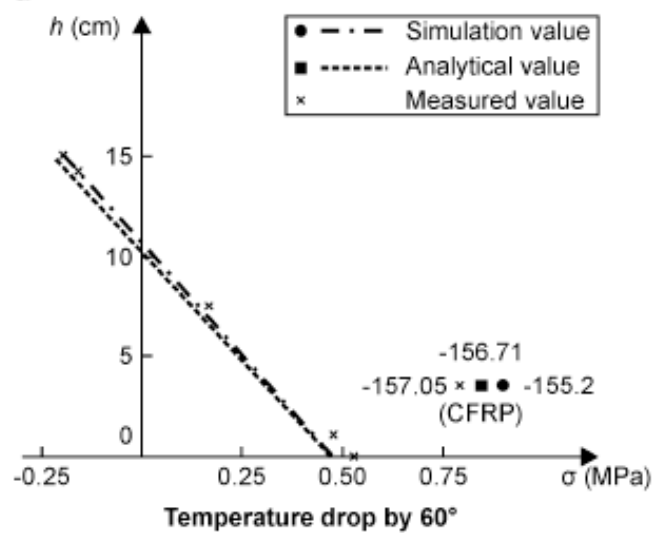

Fig. (16). Relationship between thermal stress and beam height. 
the influence of temperature difference, transverse tensile stress was produced at the concrete interface and transverse pressure stress, on the CFRP. The larger the difference, the greater the temperature stress becomes, which is disadvantageous for bonding between concrete and CFRP.

In terms of time and cost, the analytic method is the simplest and most economical method, and it has sufficient accuracy, too. Equations (8) and (9) can be used to calculate the thermal stress in practice when studying the strengthening of materials.

In equations (8) and (9), the thermal stress has a relationship with the size and elasticity modulus of concrete and CFRP sheet, which is a nonlinear function with arguments like these. To analyze the influence of these arguments, based on the experimental data shown in Fig. (4), other arguments are controlled; specifically, the CFRP elasticity modulus $E_{c f}$, concrete elasticity modulus $E_{c}$, beam height $h$, CFRP sheet thickness $\delta$, and CFRP expansion coefficient $\alpha_{c f}$ are consecutively changed, and the thermal stress changing rule for CFRP-reinforced concrete is calculated, as shown in Table 2.

Table 2 shows that the elasticity modulus of CFRP has a remarkable influence on the thermal stress. When the temperature drop is $60^{\circ} \mathrm{C}$ and $E_{c f}$ is $500 \mathrm{GPa}$, the thermal tensile stress of concrete reaches $47.6 \%$ of the standard strength of C30 concrete. The elasticity modulus of concrete has little effect on the thermal stress, indicating that the influence of concrete grades on thermal stress can be ignored. With an increase in beam height, the thermal tensile stress reduces

Table 2. Thermal stress on interface between CFRP sheet and concrete MPa.

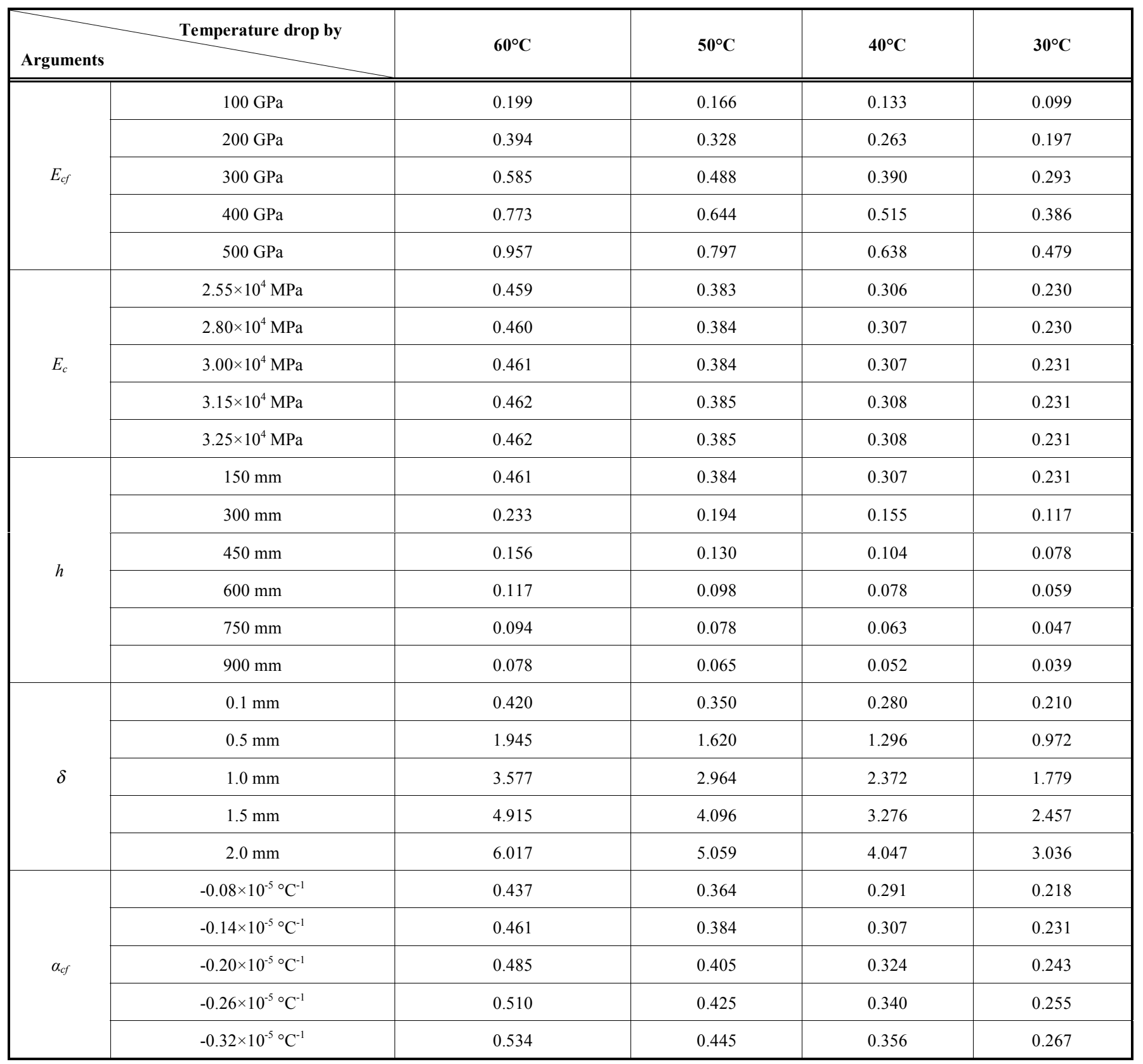


sharply. When the temperature drop is $60^{\circ} \mathrm{C}$ and beam height is $900 \mathrm{~mm}$, the thermal tensile stress of concrete is $3.9 \%$ of the standard strength of $\mathrm{C} 30$ concrete. With an increase in the CFRP sheet thickness, the thermal tensile stress increases sharply. When the temperature difference is $60^{\circ} \mathrm{C}$ and CFRP sheet thickness is $2 \mathrm{~mm}$, the thermal tensile stress of concrete is $299.4 \%$ of the standard strength of C30 concrete. With an increase in the CFRP expansion coefficient, the thermal tensile stress increases. When the temperature difference is $60^{\circ} \mathrm{C}$ and $\alpha_{c f}$ is $-3.2 \times 10^{-6}{ }^{\circ} \mathrm{C}^{-1}$, the thermal tensile stress of concrete is $0.534 \mathrm{MPa}$, which is $26.6 \%$ of the standard strength of C30 concrete. The above analysis demonstrates that the elasticity modulus and thickness of the CFRP sheet are the main factors affecting the thermal stress; in comparison, the expansion coefficient and beam height have lesser effect on the thermal stress; finally, the concrete grade has little effect on the thermal stress and can be ignored.

\section{Prevention of Thermal Stress}

Thermal stress can be prevented by pre-stressing the CFRP sheet and reinforcing concrete beam. If the tension strain on the CFRP sheet is $\varepsilon_{c f}$, after being bonded to the beam, the tensioning force is $\varepsilon_{c f} E_{c f} A_{c f}$, which causes internal forces in concrete:

$N_{y}=\varepsilon_{c f} E_{c f} A_{c f}$

$M_{y}=\varepsilon_{c f} E_{c f} A_{c f} \gamma$

Pre-stressing the CFRP sheet causes stress on the superior border of the concrete beam:

$\begin{gathered}\sigma_{\text {superior border of concrete beam }} \\ \sigma_{\text {inferior border of concrete beam }}\end{gathered}=-\frac{\varepsilon_{c f} E_{c f} A_{c f}}{A_{c}} \pm \frac{\varepsilon_{c f} E_{c f} A_{c f} \gamma \gamma_{1}}{I_{c}}$

Equations (8) and (9) can be substituted into equation (11) to obtain the stress caused by the temperature difference in a concrete beam reinforced by a prestressed CFRP sheet:
$M=\frac{E_{c} I_{c} \varepsilon_{c}}{r_{1}}$

Using equations (14) and (15),

$f=\frac{5 l^{2} \varepsilon_{c}}{48 r_{1}}$

After releasing the arch, tension strain is produced in the CFRP sheet when the beam is horizontal, $\varepsilon_{c}=\varepsilon_{c f}$ :

$f=\frac{5 l^{2} \varepsilon_{c f}}{48 r_{1}}$

Therefore, the beam is reinforced by a prestressed CFRP sheet. With the value of the pre-tension strain $\varepsilon_{c f}$, the value of the arch $f$ can be calculated; arch bonding can then be conducted according to $f$, and after releasing the arch, the beam can prevent thermal stress.

\section{CONCLUSION}

This study tested four CFRP-reinforced concrete specimens using a resistance strain gauge, incubator, and lowtemperature freezer. The isoperibol is taken as $20^{\circ} \mathrm{C}$, and $10^{\circ} \mathrm{C},-20^{\circ} \mathrm{C},-30^{\circ} \mathrm{C}$, and $-40^{\circ} \mathrm{C}$ are taken as the lowtemperature environment. The thermal stress of the three concrete specimens is measured for temperature differences of $30^{\circ} \mathrm{C}, 40^{\circ} \mathrm{C}, 50^{\circ} \mathrm{C}$, and $60^{\circ} \mathrm{C}$. Using the obtained data, the change rule of low-temperature stress of CFRP-reinforced concrete beams is analyzed. The results show good agreement with the theoretical analysis and analog simulation. The following conclusions are drawn from this study:

- With the effect of temperature difference, tensile stress is produced at the interface of concrete; when the temperature drops to $60^{\circ} \mathrm{C}$, the maximum tensile stress is close to $0.5 \mathrm{MPa}$, which is $24.8 \%$ of the $\mathrm{C} 30$ concrete standard strength, which should not be ignored. Therefore, in cold

$$
\begin{aligned}
& \underset{\sigma_{\text {inferior border of concrete beam }}}{\sigma_{\text {merior border of concrete beam }}}=\frac{E_{c} A_{c} E_{c f} A_{c f}\left(E_{c} I_{c}+E_{c f} I_{c f}\right)\left(\alpha_{c}-\alpha_{c f}\right) \Delta t}{\left(E_{c} A_{c}+E_{c f} A_{c f}\right)\left(E_{c} I_{c}+E_{c f} I_{c f}\right)+\gamma^{2} E_{c} A_{c} E_{c f} A_{c f}}\left(\frac{1}{\mathrm{~A}_{c}} \mp \frac{E_{c} \gamma_{1}}{E_{c} I_{c}+E_{c f} I_{c f}}\right)-\frac{\varepsilon_{c f} E_{c f} A_{c f}}{A_{c}} \pm \frac{\varepsilon_{c f} E_{c f} A_{c f} \gamma_{1}}{I_{c}} \\
& \begin{array}{l}
\sigma_{\text {superior border of CFRP sheet }} \\
\sigma_{\text {inferior border of CFRP sheet }}
\end{array}=\frac{E_{c} A_{c} E_{c f} A_{c f}\left(E_{c} I_{c}+E_{c f} I_{c f}\right)\left(\alpha_{c}-\alpha_{c f}\right) \Delta t}{\left(E_{c} A_{c}+E_{c f} A_{c f}\right)\left(E_{c} I_{c}+E_{c f} I_{c f}\right)+\gamma^{2} E_{c} A_{c} E_{c f} A_{c f}}\left(-\frac{1}{A_{c f}} \mp \frac{E_{c f} \gamma \gamma_{2}}{E_{c} I_{c}+E_{c f} I_{c f}}\right)+\varepsilon_{c f} E_{c f}
\end{aligned}
$$

Equations (12) and (13) can be used to calculate the strain value $\varepsilon_{f}$ needed to prevent thermal stress in the CFRP sheet.

In the third part of reference [13], a simple method for pre-stressing was proposed [13]. First, the beam should be arched; second, the CFRP sheet should be bonded to the bottom of beam; and third, the arch should be released to produce pre-stress in the CFRP sheet. If the arch is denoted by $f$ and the beam span, by L, the bending moment across the beam span is

$$
M=\frac{48 E_{c} I_{c} f}{5 l^{2}}
$$

After arching, if compressive strain $\varepsilon_{c}$ is produced in a section of the concrete span's inferior border, bending moment is produced across the beam span: areas, low-temperature thermal stress should be taken into account when reinforcing concrete or concrete beams.

- When the temperature drops to $60^{\circ} \mathrm{C}$, thermal pressure stress is produced on the CFRP sheet, the maximum pressure stress reaches $156.71 \mathrm{MPa}$; this is $\sim 3.7 \%$ of the design strength of $4200 \mathrm{MPa}$, which can be ignored.

- In contrastive analysis, the analytic equations are relatively precise. The elasticity modulus and CFRP sheet thickness are the main factors affecting the thermal stress; the expansion coefficient and beam height are inferior factors affecting the thermal stress; finally, the concrete grade has little effect on thermal stress.

- Thermal stress can be prevented by prestressing the CFRP sheet and reinforcing the concrete beam. To re- 
duce low-temperature thermal stress, the equation of this method is derived in this study.

\section{NOTATIONS USED IN IMAGES}

$$
\begin{aligned}
& d M_{c}=\text { Increment of bending moments of sections of con- } \\
& \text { crete } \\
& d M_{c f}=\text { Increment of bending moments of sections of } \\
& \text { CFRP sheets } \\
& d N_{c}=\text { Increment of axial forces on the centers of sections } \\
& \text { of concrete } \\
& d N_{c f}=\text { Increment of axial forces on the centers of sections } \\
& \text { of CFRP sheets } \\
& d \chi \quad=\quad \text { Structural unit length } \\
& h=\text { Beam height } \\
& \mathrm{i}=\text { Specimen number } \\
& \mathrm{J}=\text { Temperature environment of specimens } \\
& M_{c}=\text { Bending moments of sections of concrete } \\
& M_{c f}=\text { Bending moments of sections of CFRP sheets } \\
& N_{l} \quad=\text { Strain gauge bonded to CFRP } \\
& N_{2}=\text { Strain gauge bonded to bottom of concrete beam } \\
& N_{3}=\text { Strain gauge bonded to half height of concrete }
\end{aligned}
$$

\section{CONFLICT OF INTEREST}

The authors confirm that this article content has no conflict of interest.

\section{ACKNOWLEDGEMENTS}

This project was funded by the Science and Technology Research Project, Ministry of Education, Liaoning Province (L2012097).

\section{REFERENCES}

[1] L. Bisby and T. Stratford, "Design for fire of concrete elements strengthened or reinforced with fibre-reinforced polymer: State of the art and opportunities from performance-based approaches," Canadian Journal of Civil Engineering, vol. 40, no. 11, pp. 103443, 2013.

[2] R. A. Hawileh, M. Naser and H. A. Rasheed, "Thermal-Stress finite element analysis of CFRP strengthened concrete beam exposed to top surface fire loading," Mechanics of Advanced Materials and Structures, vol. 18, no. 3, pp. 172-80, 2011.

[3] M. M. Rafi and A. Nadjai, "Behavior of Hybrid (Steel-CFRP) and CFRP bar-reinforced concrete beams in fire," Journal of Composite Materials, vol. 45, pp. 1573-84, 2011.

[4] R. A. Hawileh, M. Nasser, W. Zaidan and H. A. Rasheed, "Modeling of insulated CFRP-strengthened reinforced concrete Tbeam exposed to fire," Engineering Structures, vol. 31, no. 12, pp. 3072-79, 2009

[5] T. J. Stratford and L. A. Bisby, "effect of warm temperatures on externally bonded FRP strengthening," Journal of Composite for Construction, vol. 16, no. 3, pp. 235-44, 2012.

[6] H. Bellakehal, A. Zaidi, R. Masmoudi and M. Bouhicha, "Combined effect of sustained load and Freeze-Thaw cycles on one-way concrete slabs reinforced with glass fibre-reinforced polymer," Canadian Journal of Civil Engineering, vol. 40, no. 11, pp. 1060-7, 2013.

[7] C. Brauner, T. B. Block, H. Purol and A. S. Herrmann, "Microlevel manufacturing process simulation of carbon fiber/epoxy composites to analyze the effect of chemical and thermal induced residual stresses," Journal of Composite Materials, vol. 46, pp. 2123-43, 2012.

[8] H. A. Rasheed, M. Nassajy, S. Al Subaie, S. M. Abrishamchian and A. Al Tamimi, "Suppressing delamination failure mode in concrete beams strengthened with short CFRP laminates," Mechanics of Advanced Materials and Structures, vol. 18, no. 3, pp. 194-200, 2011.

[9] J. -P. Won and C. -G. Park, "Effect of environmental exposure on the mechanical and bonding properties of hybrid frp reinforcing bars for concrete structures," Journal of Composite Materials, vol. 40, pp. 1063-76, 2006.

[10] C. C. Spyrakos, I. G. Raftoyiannis, L. Credali and J. Ussia, "Experimental and analytical study on reinforced concrete beams in bending strengthened with FRP," The Open Construction and Building Technology Journal, vol. 8, pp. 153-63, October 2014. [Online] Available: http://benthamopen.com/tobctj/articles/ V008/153TOBCTJ.pdf [Accessed Oct. 01, 2014].

[11] C. B. Demakos, C. C. Repapis and D. Drivas, "Investigation of structural response of reinforced concrete beams strengthened with anchored FRPs," The Open Construction and Building Technology Journal, vol. 7, pp. 146-57, November 2013. [Online] Available: http://benthamopen.com/tobctj/articles/V007/TOBCTJ131014004. pdf [Accessed Oct. 14, 2013].

[12] G. J. Mitolidis, T. N. Salonikios and A. J. Kappos, "Mechanical and bond characteristics of SRP and CFRP Reinforcement $-\mathrm{A}$ Comparative Research," The Open Construction and Building Technology Journal, vol. 2, pp. 207-216, August 2008. [Online] Available: http://benthamopen.com/tobctj/articles/V007/ TOBCTJ131014004.pdf [Accessed August 2008].

[13] T. Jinguang, C. Jianfei, S. T. Smith, FRP Strengthened RC Structure, Beijing: China Architecture Press, 2004, pp. 32-35 (in Chinese). 